\title{
Fatigue behaviour of pseudo-ductile unidirectional thin-ply carbon/epoxy- glass/epoxy hybrid composites
}

\author{
Putu Suwarta ${ }^{\mathrm{a}, *}$, Mohamad Fotouhi ${ }^{\mathrm{b}}$, Gergely Czél ${ }^{\mathrm{c}}$, Marco Longana ${ }^{\mathrm{a}}$, Michael R. Wisnom ${ }^{\mathrm{a}}$ \\ ${ }^{\text {a } B r i s t o l ~ C o m p o s i t e s ~ I n s t i t u t e ~(A C C I S), ~ U n i v e r s i t y ~ o f ~ B r i s t o l, ~ B S 8 ~ 1 T R ~ B r i s t o l, ~ U n i t e d ~ K i n g d o m ~}$ \\ ${ }^{\mathrm{b}}$ Department of Design and Mathematics, The University of the West of England, BS16 1QY Bristol, United Kingdom \\ ${ }^{\mathrm{c}}$ Department of Polymer Engineering, Budapest University of Technology and Economics, Múegyetem rkp. 3, H-1111 Budapest, Hungary
}

\section{A R T I C L E I N F O}

\section{Keywords:}

Hybridisation

Unidirectional

Fatigue

Delamination

Strain energy release rate

\begin{abstract}
A B S T R A C T
This paper is the first detailed investigation of the fatigue behavior of pseudo-ductile unidirectional (UD) thinply interlayer hybrids made of thin-ply carbon/epoxy plies sandwiched between standard thickness glass/epoxy plies under two scenarios: without any initial damage (pristine hybrids) and after the introduction of damage in the laminates by loading past the pseudo-yield point (overloaded hybrids). The laminates were subjected to different percentages of the critical stress level at which multiple fragmentation of the carbon plies was established (knee-point stress). The stress levels for fatigue delamination initiation and growth were evaluated experimentally. Based on the experimental work, it was observed that (1) when pristine hybrid composites were fatigued well below the carbon failure strain, at a stress level of $80 \%$ of the knee-point stress, there is no stiffness reduction after a significant number of cycles $\left(10^{5}\right.$ cycles) (2) gradual stiffness reduction and very slow delamination growth was observed for pristine hybrid composites when fatigued at $90 \%$ of the knee-point stress, (3) when overloaded hybrid composites were fatigued at $90 \%, 80 \%$ and $70 \%$ of the knee-point stress, they did not fail immediately but delaminated slowly (4) the slow growth was due to the low energy release rate of the thinply hybrid composites (5) the strain energy release rate approach related to delamination rates provides a good way to characterize the fatigue damage accumulation of overloaded hybrid composites and as a basis to predict the fatigue life.
\end{abstract}

\section{Introduction}

Fibre reinforced composites offer outstanding combinations of strength and stiffness together with low density [1], making them an attractive choice of material for lightweight structural applications such as wind turbine blades [2], sports equipment [3], spacecraft and aerostructures [4], motorsport [5], where weight saving, and durability are major concerns. However, the limitation of these materials is the catastrophic failure mode without significant damage or warning before failure and little residual load carrying capacity [6]. Conservative design limits and larger safety margins are usually applied for composites to compensate for their brittle failure. To overcome this problem, a new generation of high-performance composites with pseudo-ductile or ductile behaviour delivering progressive, safe failure mechanisms like metals' yielding, detectable warning and a wide margin before final failure is needed.

The most straightforward way to impart ductility into fibre reinforced composite materials is to replace their brittle constituents (i.e. glass, carbon fibres, and thermosetting polymer resins) with new inherently ductile materials. Because the mechanical properties of composites are fibre dominated, the focus has been on developing stiff and ductile fibres. Annealed stainless steel fibres (diameter of 5-100 $\mu \mathrm{m}$ ) with tensile failure strain up to $20 \%$ and stiffness of $193 \mathrm{GPa}$ were investigated as an alternative reinforcement for ductile composites using various polymer matrix materials by Allaer et al. [7] and Callens et al. [8-10], while Swolfs et al. [11] hybridised stainless steel fibres with self-reinforced polypropylene composites. From their work, excellent toughness and ductile behaviour of fibre composites were reported although the density of the obtained fibre composites was at least double that of carbon/epoxy, which hinders their suitability for lightweight applications. Promising new materials such as nanotube fibres [12] showing up to $6 \%$ tensile strain to failure are still facing challenges to make them suitable for lightweight structural application due to their long verification and commercialisation process.

Mixing different type of fibres either by comingling them [13-15] or creating ply-by-ply laminates [16-18] is a simple approach to improve

\footnotetext{
* Corresponding author.

E-mail address: ps14474@bristol.ac.uk (P. Suwarta).
} 
the brittle failure mode of conventional fibre composites by potentially making it more gradual. Previous work on hybrids made of unidirectional (UD) layered glass/carbon has seen sudden drops of stress after the low strain material breaks, which correlate to the unstable delamination of the failed layers due to the high strain energy release rate [16]. Bunsell and Harris [18] observed gradual failure and multiple cracking of carbon plies without unstable delamination in their UD layered glass/carbon hybrid incorporating $0.4-0.8 \mathrm{~mm}$ thick carbon layers. The reason for the gradual failure type despite the carbon thickness is believed to be a low strain energy release rate due to low carbon fibre failure strains $(0.26 \%)$, which was insufficient to drive delamination. Manders and Bader [19] investigated the effect of carbon layer thickness on the failure mode of UD glass-carbon-glass sandwich laminates, and it was reported that by using thinner central carbon layer, the extent of delamination between layers was reduced.

Including new technology such as thin carbon prepregs has been shown to improve the mechanical properties of quasi-isotropic composites under various loading conditions [20-23] towards higher failure strains due to suppression of matrix cracking and delamination. The reason for this behaviour is that thinner plies have lower energy release rates, thereby delaying the propagation of inter- and intralaminar cracks. Based on the summarised work on hybrid and thin-ply prepregs, Czél et al. [24,25] investigated the mechanical properties and failure modes of UD interlayer glass/carbon hybrids incorporating thin carbon plies under tensile loading. The glass-carbon hybrid composites show progressive damage mechanisms (i.e. fragmentation of carbon layers) and stable dispersed delamination after the first carbon layer fracture due to the low energy released [24] resulting in a pseudo-ductile failure response [26]. The so-called stable delamination refers to stable pull out of the fragmented carbon layers from the undamaged glass layers, which prevents the catastrophic failure of the hybrid composite after the first carbon layer fracture. To achieve the desirable pseudo-ductile responses in hybrid composites under tensile loading, appropriate material properties, and suitable values of relative thickness (i.e. thickness ratio of low strain material (LSM) to high strain material (HSM) and absolute thickness of low strain material (LSM) need to be selected, as guided by the design framework developed by Jalalvand et al. [27-29].

Structural components made of hybrid fibre composites are often subjected to cyclic loading and understanding their long-term behaviour is important as this could help to predict their lifetime and schedule future maintenance. Several authors [30-32] have reported experimental results for the fatigue behaviour of hybrid composites. The tensile fatigue response of basalt/carbon fabric hybrid composites were explored by Wu et al. [30]. The S-N (strength versus number of cycles) curves were shifted to higher numbers of cycles, in comparison to the all basalt fibre composites, when fatigued at $90 \%, 80 \%$ and $70 \%$ of their respective ultimate tensile strength. They attributed this behaviour to the different strain to failure between the basalt and carbon fibres where the basalt fibres with higher strain to failure prevents the continuous fracture of the carbon fibres and the rough surface of basalt fibres [33] contributed to mechanical interlocking between the basalt and carbon layers thus promoting sufficient bonding between them, thereby delaying the delamination propagation. The fatigue results of Dickson et al. [31] for UD glass-carbon hybrids showed a lower slope for the hybrid's S-N curve compared with that of the pure glass and pure carbon composites for a range of fatigue load level from $40 \%$ and $90 \%$ of their respective ultimate tensile strength. Peijs et al. [32] also discovered a flat S-N curve for UD hybrid composites made of high-performance polyethylene (HP-PE) and carbon fibre intermingled tow hybrids with a high degree of dispersion compared to the pure carbon composites when they were fatigued between $50 \%$ and $90 \%$ of their respective static tensile strength. Dai et al. [34] presented a 3D model to describe the fatigue behaviour of UD glass/carbon hybrid composites under tension-tension. It was demonstrated in their paper [34] that an improvement in the fatigue lifetime of hybrid composites compared to the all glass fibre composites was attainable. This was possible because further cracks propagating from the lower strain carbon fibres were delayed by the presence of the higher strain glass fibres, thus reducing the likelihood of further carbon fibre failure and improving the fatigue lifetime of the hybrid composites. Based on the fatigue damage mechanisms observed in their modelling work [34], it was suggested to increase the fibre dispersion to improve the damage resistance. Based on the above-mentioned work on characterising the fatigue behaviour of UD hybrid composites [30-32,34], there is a benefit in fatigue in using two fibres with a different strain to failure. The higher strain fibres prevent further rapid crack extension from the first failed lower strain fibres. This leads to slower fatigue damage propagation and enhances the number of cycles to failure. Furthermore, the tensile fatigue resistance of hybrid composites can be improved by: (1) increasing the dispersion between the reinforced fibres and, (2) increasing the adhesion between the low and high modulus fibres by using surface treatment. Although the fatigue response of other hybrid composites was already reported as mentioned above, the fatigue behaviour of pseudoductile hybrid composites made of UD interlayer thin carbon/glass hybrids has not been explored before according to the author's best knowledge.

The tensile fatigue behaviour of thin-ply quasi-isotropic (QI) carbon laminates reported by Sihn et al. [20] has shown superior mechanical properties (higher residual tensile strength) compared to the quasiisotropic thick ply laminates up to $5.10^{4}$ cycles at $60 \%$ of the ultimate tensile strength of the QI thin specimens. The reason behind this is the absence of microcracks and delamination for the thin-ply specimens due to the low energy release rate.

A power-law relation between delamination growth and energy release rate was discovered by O'Brien [35] for a QI carbon composite when it was tension fatigued. At the three-fatigue loading levels, $86 \%$, $93 \%$ and $100 \%$ of the maximum failure strain, the delamination grew from the edge of the specimen towards the centre. A linear relation between the stiffness loss and delamination growth was also observed and based on this, measurement of stiffness was also proposed to determine the extent of damage during fatigue loading.

The current paper differs from other work on the fatigue of hybrid composites e.g. [30-32], as fragmentation of the stiffer constituents never occurred on their specimens during fatigue loading. Some initial results on the effect of progressive fragmentation of the stiffer constituents on the fatigue behaviour of UD thin-ply carbon/glass hybrid composites have been presented by Suwarta et al. [36], but this paper is the first detailed characterisation of the fatigue behaviour of UD thinply carbon/glass hybrid composites. Also according to the author's best knowledge, there is no other published work on the fatigue behaviour of UD thin-ply carbon/glass hybrid composites. Two scenarios are investigated: (1) before any damage is introduced (pristine hybrids) and (2) after the introduction of damage (overloaded hybrids). Based on this study, a safe fatigue load level for UD thin-ply carbon/glass hybrid composites together with damage evolution characterisation and the relation between energy release rate and damage growth is presented. The comparison between the fatigue behaviour of UD thin-ply carbon/ glass hybrid composites with its constituent parent materials is outside the scope of this paper.

\section{Experimental}

\subsection{Materials}

The hybrid composite constituent materials considered for the design and used in the experimental part of the study were a) standard thickness unidirectional (UD) prepreg made of S-glass reinforced epoxy supplied by Hexcel and b) thin-ply UD prepreg made from carbon reinforced epoxy commercially available from SK Chemicals under the trade name of SkyFlex USN020A. The epoxy resin systems in the prepregs were the aerospace grade 913 (Hexcel) and K50 (SK Chemicals). The good integrity of the hybrid laminates was confirmed during the 
Table 1

Fibre properties of the applied UD prepregs based on manufacturer's data.

\begin{tabular}{|c|c|c|c|c|c|c|}
\hline Fibre type & Fibre manufacturer & $\begin{array}{l}\text { Elastic modulus } \\
{[\mathrm{GPa}]}\end{array}$ & $\begin{array}{l}\text { Strain to failure } \\
\text { [\%] }\end{array}$ & $\begin{array}{l}\text { Tensile strength } \\
\text { [GPa] }\end{array}$ & $\begin{array}{l}\text { Density } \\
{\left[\mathrm{g} / \mathrm{cm}^{3}\right]}\end{array}$ & $\begin{array}{l}\text { CTE } \\
{[1 / \mathrm{K}]}\end{array}$ \\
\hline Tairyfil TC35 & Formosa & 240 & 1.60 & 4.0 & 1.80 & $-4.10^{-7}[37]$ \\
\hline FliteStrand S ZT S-glass & Owens Corning & 88 & $5.50^{\mathrm{a}}$ & $4.8-5.1$ & 2.45 & $2.10^{-6}[37]$ \\
\hline
\end{tabular}

a Measured on single fibre tests.

Table 2

Cured ply properties of the applied UD prepregs (Number in bracket indicates the coefficient of variation in relative \%).

\begin{tabular}{|c|c|c|c|c|c|c|}
\hline Prepreg material & Manufacturer & $\begin{array}{l}\text { Fibre areal mass } \\
{\left[\mathrm{g} / \mathrm{m}^{2}\right]}\end{array}$ & $\begin{array}{l}\text { Cured ply thickness } \\
{[\mathrm{mm}]}\end{array}$ & $\begin{array}{l}\text { Fibre volume fraction } \\
{[\%]}\end{array}$ & $\begin{array}{l}\text { Initial Stiffness } \\
{[\mathrm{GPa}]}\end{array}$ & $\begin{array}{l}\text { Strain to failure } \\
{[\%]}\end{array}$ \\
\hline TC35/epoxy & SK chemicals & $22^{\mathrm{c}}$ & $0.027^{\mathrm{a}}$ & $46.9^{\mathrm{a}}$ & $114.3^{\mathrm{a}}$ & $1.95^{\mathrm{b}}(7.08 \%)$ \\
\hline S-glass/epoxy & Hexcel & $190^{c}$ & $0.155^{\mathrm{a}}$ & $50^{\mathrm{a}}$ & $45.7^{\mathrm{a}}$ & $3.98[38]$ \\
\hline
\end{tabular}

a Calculated based on manufacturer's data.

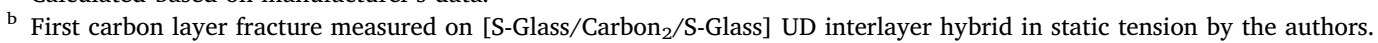

c Based on manufacturer's data.

test procedures and no layer separation was seen on cross-sectional micrographs. Material data of the applied fibres and prepreg systems can be found in Tables 1 and 2 .

The baseline strain to failure for TC35/epoxy is an average of 5 specimen measurements in a [S-Glass/Carbon ${ }_{2} / \mathrm{S}$-Glass] type sandwich hybrid specimen and it is defined as the first carbon ply crack visible in the specimen during static tensile loading. It should be noted that the strain to failure for TC35/epoxy was measured from a thin hybrid configuration, so it is expected there is a 'hybrid effect' [39] enhancement in the measured strain.

\subsection{Manufacturing}

The UD interlayer hybrid laminates consisting of thin carbon and standard thickness glass prepregs were laid upon a flat aluminium tool plate in the following sequence [SG/ $\mathrm{C}_{2} / \mathrm{SG}$, where SG stands for the S2-glass plies and $C$ for the carbon plies. The vacuum bagged laminates were then cured in an autoclave at the recommended cure temperature and pressure cycle for Hexcel 913 epoxy resin $\left(60 \mathrm{~min} @ 125^{\circ} \mathrm{C}\right.$, $0.7 \mathrm{MPa}$ ). The constituent prepregs were found to be compatible, even though the suppliers provided no details on the chemical formulation. A diamond cutting wheel was used to fabricate the individual specimens. To protect the specimens from the high clamping force and avoid premature failure in the gripping region, end tabs with $1.6 \mathrm{~mm}$ thickness, made of glass/epoxy balanced fabric reinforced plates supplied by Heathcotes Co. Ltd., were bonded to the specimens using an Araldite 2014 epoxy adhesive supplied by Huntsman and cured for 60 min@ $70{ }^{\circ} \mathrm{C}$ inside a fan convection oven.

\subsection{Specimen geometry}

The geometry of the hybrid laminates used in the experimental part of the study were UD, parallel sided tensile specimens with the following nominal dimensions 240/160/20/0.356 mm-overall length (L)/ gauge length $\left(\mathrm{L}_{\mathrm{f}}\right) /$ width $(\mathrm{W}) /$ nominal thickness $(\mathrm{h})$ respectively (see Fig. 1). The notation $t_{c}$ and $t_{g}$ in Fig. 1 refers to the nominal thickness of carbon and glass layers respectively.

For the particular specimen configuration used in this experiment, the nominal carbon/glass thickness ratio is $14.83 \%$ based on the nominal cured ply thickness for glass and carbon prepregs plies from Table 2.

\subsection{Test procedure}

Static tension and tension-tension fatigue tests were performed on

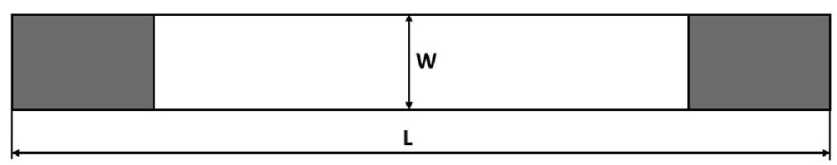

(a)

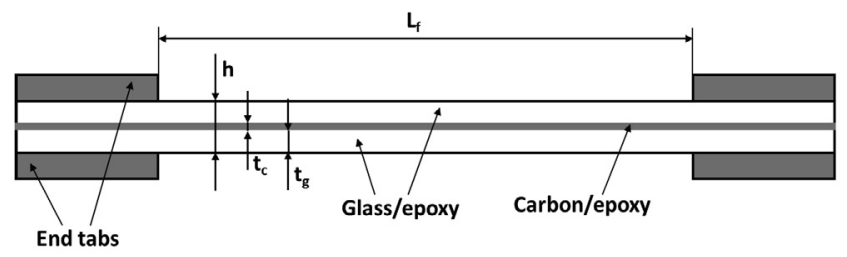

(b)

Fig. 1. Schematic of the $\left[S G / C_{2} / S G\right]$ sandwich specimen types shown from the top (a) and side view (b).

the UD interlayer thin-ply hybrid laminates at room temperature on a computer controlled Instron 8872 type $25 \mathrm{kN}$ rated universal hydraulic test machine with wedge type hydraulic grips. For the static tests, the hybrid specimens were loaded in uniaxial tension under displacement control using a crosshead speed of $2 \mathrm{~mm} / \mathrm{min}$. Strains were measured using an Imetrum video gauge system with 5 Megapixel resolution and a nominal gauge length of $130 \mathrm{~mm}$. Five specimens were tested in static tension to determine the fragmentation initiation stress level referred to as the knee-point stress $\left(\sigma_{\mathrm{k}}\right)$. The knee-point stress $\left(\sigma_{\mathrm{k}}\right)$ together with the strain $\left(\varepsilon_{\mathrm{k}}\right)$ are found from the intersection of lines fitted to the initial linear (red line) and plateau (green line) parts of the stress-strain curve as shown in Fig. 2. The saturated stress $\left(\sigma_{s}\right)$ and strain $\left(\varepsilon_{s}\right)$ shown in Fig. 2 are determined by the intersection of lines fitted to the plateau (green line) and the second rising parts (blue line) of the stress-strain curve. The notation knee-point $(\mathrm{k})$ and saturation (s) are the damage states of the hybrid during tensile loading which is explained in Section 6.1. The inserted image of a damaged hybrid specimen shown in Fig. 2 displays localized delaminations surrounding the carbon ply cracks. Well bonded areas appear black and the locally delaminated areas just around the cracks in the carbon layer are visible as the lighter areas due to the translucent nature of the glass/epoxy outer layers of the hybrid laminate. It should be noted that the inserted image in Fig. 2 was recorded using the video gauge system.

The fatigue testing was performed for two different scenarios, pristine and overloaded hybrid laminates. The pristine specimens were fatigued at two different stress levels below $\sigma_{\mathrm{k}}(90 \%$ and $80 \%)$. For the pristine case, four specimens for each load level were tested. It should 


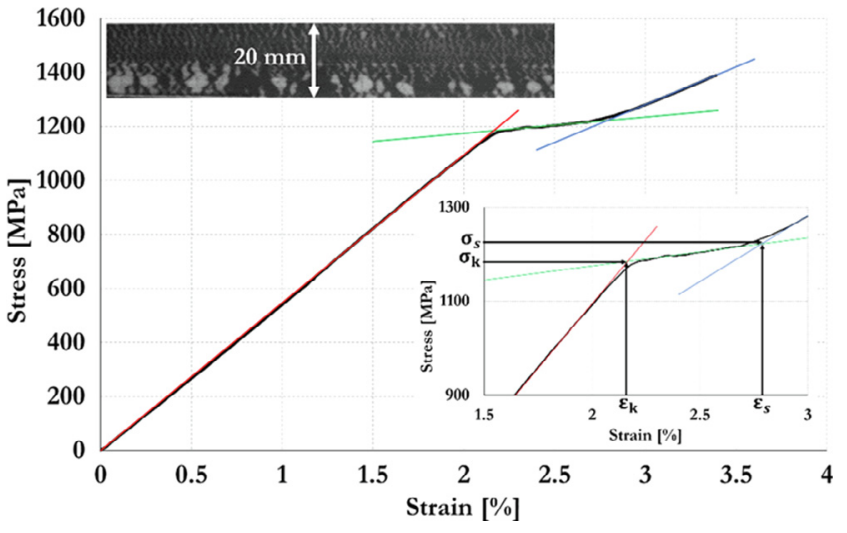

Fig. 2. Typical stress-strain response of $\left[S G / C_{2} / S G\right]$ configuration displaying $\sigma_{k}$ and $\varepsilon_{\mathrm{k}}$ as the knee-point stress and strain. The inserted image shows the damage state of the specimen at $3.4 \%$ strain.

be noted that the knee-point stress $\left(\sigma_{\mathrm{k}}\right)$ used as a reference in the case of fatigue testing of pristine specimens is taken from an average value of five hybrid composites tested in static tensile loading. To pre-fracture the other specimens, uniaxial static tensile loading was performed on the specimens under displacement control using a crosshead speed of $0.5 \mathrm{~mm} / \mathrm{min}$. The tests were stopped when the delaminated area had covered around $10-20 \%$ of the total surface area. They were then fatigued at three load levels $\left(90 \%, 80 \%, 70 \%\right.$ of $\sigma_{\mathrm{k}}$ of the particular specimen). In the case of the overloaded hybrid, four specimens each were tested at $90 \%$ and $80 \%$ load levels respectively while for the $70 \%$ load level; three specimens were tested. All fatigue tests were conducted under load control by applying a sinusoidal load around the mean load at a frequency of $2 \mathrm{~Hz}$ and a stress ratio $\left(R=\sigma_{\min } / \sigma_{\max }\right)$ of 0.1 . Overall images were recorded at increasing numbers of cycles by the Imetrum video gauge camera and the delaminated area was evaluated from the recorded images using a MATLAB code.

\section{Delamination area measurement technique}

The growth of delamination area during fatigue loading is an important damage parameter. Since the delaminated area for UD thin-ply hybrid composites is visible as explained in Section 2.4, it is possible to capture the delamination growth area and measure it. The delamination area was measured from the images collected by the video gauge using an in-house compiled MATLAB code. The images, acquired in grayscale by the Imetrum system (Fig. 3a), were imported in Matlab and cropped to cover only the specimen gauge length (Fig. 3b). Finally, they were converted into binary black and white images using a predefined
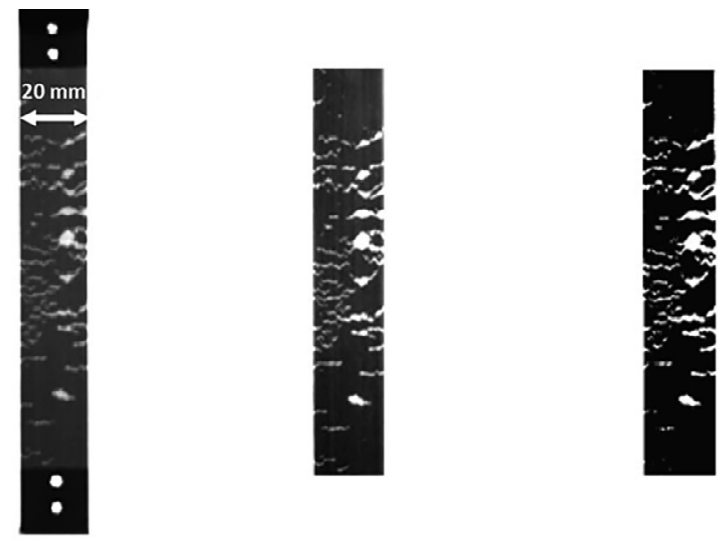

(a) Video gauge image (b) Cropped grayscale image

(c) Black and white image

Fig. 3. Image conversion process to determine the delamination area. threshold (Fig. 3c). The delaminated area was calculated by counting the white pixels; a scaling factor (dimension $\mathrm{mm}^{2}$ /pixel) allows to calculate the delaminated area in $\mathrm{mm}^{2}$. To calculate the average delamination length in mm during fatigue loading, the delaminated area is divided to the nominal width of the hybrid specimen. The four white dots shown in Fig. 3a were used to track the uniaxial strain using the video gauge system during the static loading.

\section{Stiffness reduction due to delamination}

During uniaxial fatigue loading, the longitudinal stiffness $\left(E_{N}\right)$ of composite laminates degrades as damage develops [40,41]. Because stiffness loss is easily measurable and it is a direct indication of damage, it has been proposed as a fatigue failure criterion [42]. In this work, the equation developed by O'Brien [35] to predict the stiffness loss due to delamination in composite laminates is used as shown in Eq. (1). This equation is developed based on a simple rule of mixtures.

$\frac{E_{o}-E_{N}}{E_{o}-E_{f}}=\frac{A_{N}}{A_{o}}$

where $E_{o}$, is the initial stiffness of the hybrid laminate before delamination of the central carbon layer, $E_{f}$ is the final stiffness of the hybrid laminate after the central carbon layer is fully delaminated, $E_{N}$ and $\mathrm{A}_{\mathrm{N}}$ is the stiffness and delaminated area at a certain number of cycles, $A_{o}$ is the total interfacial area. $E_{o}$ and $E_{f}$ can be expressed as in Eq. (2) and Eq. (3) respectively [24]:

$E_{o}=\frac{\left(E_{g}\left(h-t_{c}\right)+E_{c} t_{c}\right)}{h}$

$E_{f}=\frac{\left(E_{g}\left(h-t_{c}\right)\right)}{h}$

From Eq. (1), the stiffness at a certain number of cycles is given as in Eq. (4):

$E_{N}=E_{o}+\left(E_{f}-E_{o}\right) \frac{A_{N}}{A_{o}}$

Eq. (4) provides a means to correlate the observed delamination area in the UD hybrid laminate to the measured stiffness reduction.

\section{Calculation of the energy release rate}

The strain energy release rate is an important parameter to characterize delamination growth from fragmentations in the carbon plies during fatigue at a constant load level. To calculate the strain energy release rate in terms of the carbon layer stress $\left(\sigma_{\mathrm{c}}\right)$, Eq. (5) is adopted from Czel et al. [24]:

$G=\frac{\sigma_{c}^{2} t_{c}\left(E_{g}\left(h-t_{c}\right)+E_{c} t_{c}\right)}{4 E_{g} E_{c}\left(h-t_{c}\right)}$

where $E$ and $t$ is the stiffness and nominal cured layer thickness while the subscript $g$ and $\mathrm{c}$ refer to the glass and carbon layers respectively. The stress in the carbon layer can be expressed in terms of the overall applied stress $(\sigma)$, with the assumption of equal strain through the thickness of the laminate [24]:

$\sigma_{c}=\frac{\sigma h E_{c}}{E_{g}\left(h-t_{c}\right)+E_{c} t_{c}}$

The notation $\sigma$ in Eq. (6) is defined as the applied fatigue stress level which was $90 \%, 80 \%$ and $70 \%$ of $\sigma_{\mathrm{k}}$. Delamination growth under fatigue loading can be described with respect to a cyclic energy release rate $(\Delta \mathrm{G})[43]$ :

$\Delta G=G_{\max }-G_{\min }$

where $G_{\max }$ and $G_{\min }$ refer to the strain energy release rate at the maximum stress $\left(\sigma_{\max }\right)$ and minimum stress $\left(\sigma_{\min }\right)$. 


\section{Results and discussion}

\subsection{The static tensile behaviour of the UD thin-ply hybrid composites}

Fig. 2 shows a typical stress-strain curve of the UD interlayer thinply hybrid composites under static tension. During tensile loading, a recorded video taken from the specimen by the strain measurement system was visually studied to determine the first carbon layer fracture. The first appearance of carbon layer fracture of this hybrid composite is at $1.95 \%$ strain which is an average value of five specimen measurements. Starting from $2.00 \%$ strain, which is the knee-point strain $\left(\varepsilon_{\mathrm{k}}\right)$, a process of multiple carbon layer fragmentation was established resulting in a plateau on the stress-strain curve in Fig. 2. The initial carbon layer fracture and the start of fragmentation occurred at higher strain than the manufacturer's data sheet failure strain of $1.60 \%$ as shown in Table 1 . This could be attributed to the constraint provided by the adjacent glass layers to delay the formation of broken carbon fibre clusters and to delay the establishing of stable fragmentation process. The behaviour itself is known as the 'hybrid effect' and detailed explanation of this behaviour is provided by Wisnom et al. [39] which used a statistical strength model and ply level finite element model to explain and quantify the 'hybrid effect'. Upon further loading, the localized delaminations grew gradually until they almost completely joined together, with the fragmentation reaching saturation at $2.78 \%$ strain $\left(\varepsilon_{s}\right)$, and $1221 \mathrm{MPa}$ stress $\left(\sigma_{\mathrm{s}}\right)$. After this point, the additional load is carried mainly by the glass layers and the stress rises further until $3.4 \%$ strain. The inset in Fig. 2 shows a specimen after the test has been interrupted at $3.4 \%$ strain and the irregular delamination patch sizes shown are due to carbon layer thickness variation where the thicker parts tend to produce larger delamination patches. Table 3 summarises the average of the five hybrid specimens tested in static tension loading showing the important parameters such as first carbon fracture strain, knee-point stress and strain used later to determine the fatigue load level in the pristine hybrid case. These values have been corrected for the calculated residual elastic strain in the carbon layer. The coefficient of thermal expansion (CTE) of the UD composite, $\alpha_{\text {comp }}$, was calculated from Eq. (8) adopted from [37]:

$\alpha_{\text {comp }}=\vartheta_{f} \cdot \alpha_{f} \cdot \frac{E_{f}}{E_{\text {comp }}}+\left(1-\vartheta_{f}\right) \cdot \alpha_{m} \cdot \frac{E_{m}}{E_{\text {comp }}}$

where $\vartheta_{f}, \alpha_{f}$ and $E_{f}$ are the volume fraction, the CTE and the elastic modulus of the fibres respectively while $\alpha_{m}$ and $E_{m}$ are the CTE and modulus of the matrix material. Table 1 provides the CTE values for the different fibres which were taken from the product datasheets. For both epoxy matrices in the hybrid composites, typical values of $\alpha_{m}=6.10^{-5}$ $[1 / \mathrm{K}]$ and $E_{m}=3 \mathrm{GPa}$ were assumed from the general literature.

The compressive thermal residual strains were calculated from the equilibrium-force state between the carbon/epoxy and glass/epoxy layers by assuming constant strain through the thickness and a $100{ }^{\circ} \mathrm{C}$ temperature difference from the cure temperature to room temperature [37]. The calculated residual elastic strain in the carbon for the presented hybrid configuration is $-0.025 \%$ and this has been accounted for in the values in Table 3 for the strain at first carbon layer failure and at the knee-point strain.

The knee-point stress and initial stiffness were evaluated using the nominal thicknesses of the hybrid specimens assuming constant fibre areal densities and fibre volume fractions, neglecting the effect of thickness variation due to variations in resin distribution [44].

\subsection{Fatigue behaviour of the pristine UD thin-ply hybrid composites}

\subsubsection{Fatigue response}

To determine the fatigue loading level where there is no damage in the hybrid laminates, a series of fatigue tests was conducted at two different load levels: $80 \%$ of $\sigma_{\mathrm{k}}$ which is at $878.4 \mathrm{MPa}$ or in terms of strain level is at $1.60 \%$, and at $90 \%$ of $\sigma_{\mathrm{k}}$ which in terms of stress and strain is at $988.2 \mathrm{MPa}$ and $1.81 \%$ respectively. From the experimental results for the four specimens loaded at $80 \%$ of $\sigma_{\mathrm{k}}$, there was no fragmentation observed and a negligible stiffness reduction up until $10^{5}$ cycles. From the static tension test results in Section 6.1, the first carbon fracture was observed at $1.95 \%$ strain so when the hybrid composites were fatigued at $1.60 \%$ strain level, no fragmentation was observed because the strain was well below that for the first carbon fracture. Because no damage was observed at $80 \%$ of $\sigma_{\mathrm{k}}$ for the UD pristine hybrid composites, it was not necessary to conduct fatigue testing at $70 \%$ of $\sigma_{\mathrm{k}}$ for the same specimen type.

For the fatigue characterisation of the UD pristine hybrid composites at $90 \%$ of $\sigma_{\mathrm{k}}$, the specimens were tested until they delaminated. Fig. 4 shows the normalised stiffness reduction $\left(E_{N} / E_{o}\right)$ and normalised delamination growth $\left(A_{N} / A_{o}\right)$ as a function of number of cycles at $90 \%$ of $\sigma_{\mathrm{k}}$, where $E_{N}$ is the laminate stiffness at a certain number of cycles and $E_{o}$ is the initial laminate stiffness at zero cycles. To exclude the effect of thickness variations, $E_{N}$ and $E_{o}$ were evaluated using the nominal thicknesses of the hybrid specimens.

Typical stiffness reduction and delamination development for UD pristine hybrid fatigued at $90 \%$ of $\sigma_{\mathrm{k}}$ shown in Fig. 4 indicates three stages. These stages are defined based on the changes in delamination growth and stiffness reduction. It should be noted that this approach was also applied to the overloaded hybrid composites. It should be noted that the fatigue behaviour shown in Fig. 4 is for specimen 2 mentioned in Fig. 5. Initially there was negligible delamination growth in the first stage when the hybrid was fatigued from 0 to $2 \times 10^{4}$ cycles and therefore the stiffness remained constant but splitting took place at the edge of this particular specimen at $2 \times 10^{4}$ cycles, causing a $2 \%$ drop of stiffness. Although splitting had taken place, the delaminated area was compared against the original area of that laminate. In the second stage, from $22.5 \times 10^{3}-35 \times 10^{3}$ cycles, the carbon layers fragmented partially across the width, resulting in a slow localised delamination growth and stiffness loss rate. After reaching a transition point, $\mathrm{N}_{\mathrm{kp}}$, as shown in Fig. 4, the carbon fragmentations grew across the whole width resulting in an accelerated delamination growth and stiffness loss rate between $37.5 \times 10^{3}$ and $44.5 \times 10^{3}$ cycles at stage 3 . The transition point, $\mathrm{N}_{\mathrm{kp}}$, is found from the intersection of lines fitted to stage 2 and stage 3 of the graph as shown in Fig. 4. The fatigue testing was then terminated at final loading cycles, $\mathrm{N}_{\mathrm{fp}}$, when delamination had covered almost the whole area of the specimen. As indicated in Eq. (4), a linear relation is expected between stiffness loss and the growth of delaminated area, which has been confirmed from this fatigue test and is shown in Fig. 5. It should be noted that the initial stiffness was measured experimentally, and the expected final stiffness was calculated from the rule of mixtures in Eq. (3) considering that the hybrid composites lost the contribution from the central carbon layers. By comparing the first carbon fracture strain from Table 3 with the applied strain level at $90 \%$ of $\sigma_{\mathrm{k}}$, it is seen that the applied strain level of $1.81 \%$ is within the statistical range for carbon fracture to take place, and therefore it is not surprising that fragmentation events occurred during fatigue loading, which were followed by delamination. Due to the low

Table 3

Results summary of the quasi static tests (numbers in brackets indicates the coefficient of variation in relative \%), the strains are corrected for residual strains.

\begin{tabular}{|c|c|c|c|c|}
\hline Specimen Type & $\begin{array}{l}\text { Initial elastic modulus } \\
{[\mathrm{GPa}]}\end{array}$ & $\begin{array}{l}\text { Strain at first carbon layer failure } \\
{[\%]}\end{array}$ & $\begin{array}{l}\text { Strain at knee-point } \varepsilon_{\mathrm{k}} \\
{[\%]}\end{array}$ & $\begin{array}{l}\text { Stress at knee-point } \sigma_{\mathrm{k}} \\
{[\mathrm{MPa}]}\end{array}$ \\
\hline$\left[\mathrm{SG} / \mathrm{C}_{2} / \mathrm{SG}\right]$ & $53.32(2.13 \%)$ & $1.95(7.08 \%)$ & $2.00(4.82 \%)$ & $1098(6.77 \%)$ \\
\hline
\end{tabular}




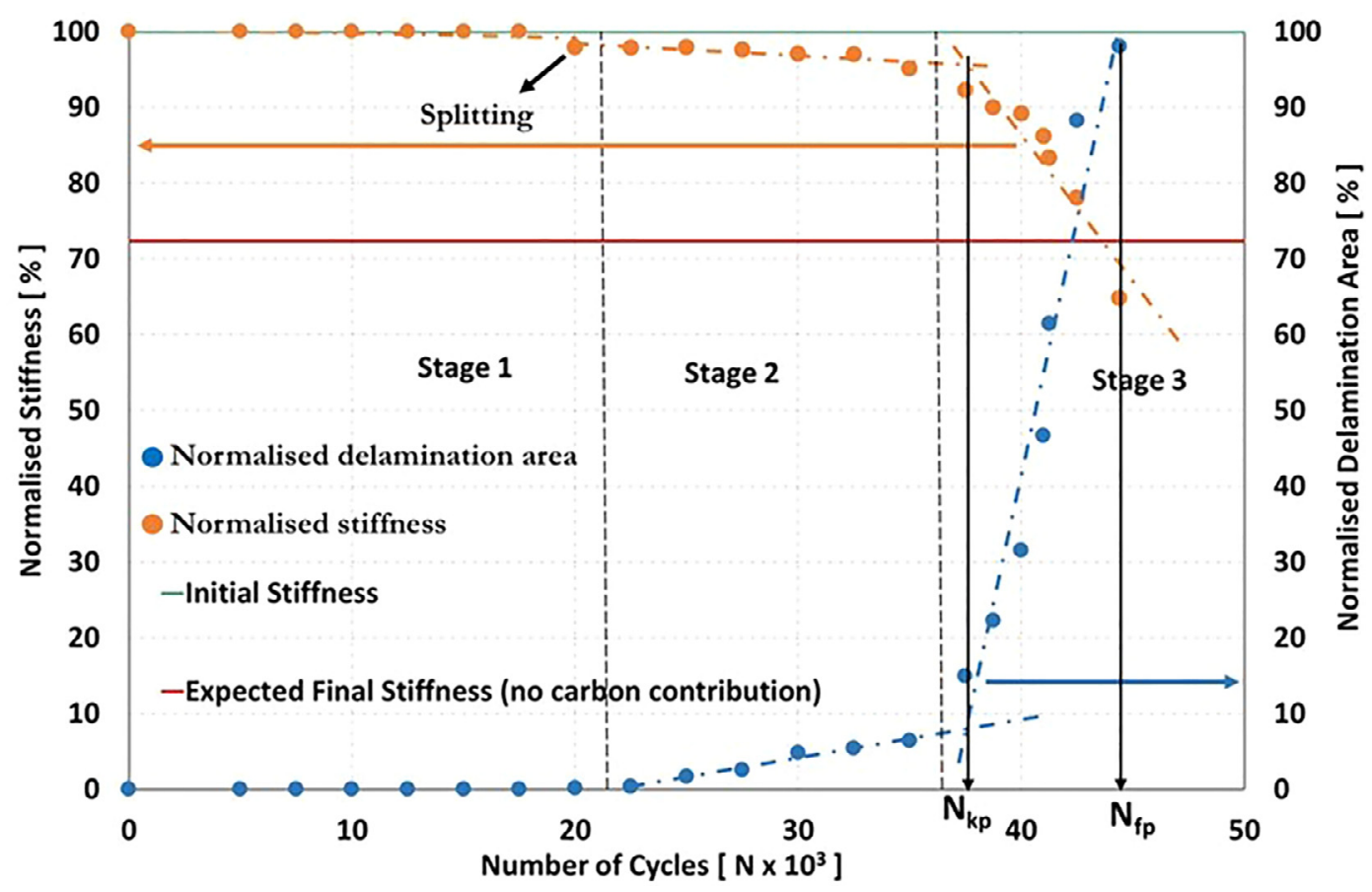

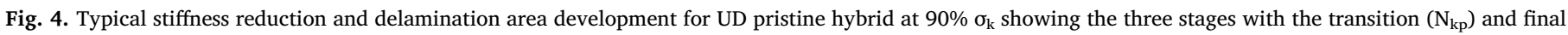
number of cycles $\left(\mathrm{N}_{\mathrm{fp}}\right)$.

energy release rate of the UD thin-ply hybrid composites determined as explained in section 5 , the delamination grew slowly with advancing number of cycles at stage 2 .

Fig. 5 shows the plot between stiffness loss and delamination growth at $90 \%$ of $\sigma_{\mathrm{k}}$ along with the predicted stiffness loss calculated by using Eq. (4) developed by O'Brien [35] based on a simple rule of mixtures. As shown in Fig. 5, there is an approximately linear relation between the stiffness loss and delamination growth obtained from the experimental results. The deviation in the results shown in Fig. 5 from the rule of mixtures is due to the different extent of splitting between individual hybrid specimens.

The predicted relation between stiffness loss and delamination growth calculated from the rule of mixtures shows that at 100\% total delamination, the hybrid should have lost $27.70 \%$ stiffness which yields a final stiffness of $72.30 \%$. The final stiffness of the tested hybrid specimens went below the expected final stiffness without any carbon contribution, due to splitting. Table 4 provides the stiffness loss rate summary at $90 \%$ of $\sigma_{\mathrm{k}}$ for the UD thin-ply hybrid composites at stages 1,2 and 3 respectively and the average number of cycles $\mathrm{N}_{\mathrm{kp}}$ and $\mathrm{N}_{\mathrm{fp}}$. The stiffness loss rates shown in Table 4 are measured by plotting a linear fitted line to the respective data at stage 2 and stage 3 respectively as shown in Fig. 4. Variability is typically high in fatigue of fibre reinforced composites, but enough specimens have been tested to provide a reasonable overall characterization of the behavior. Comparing

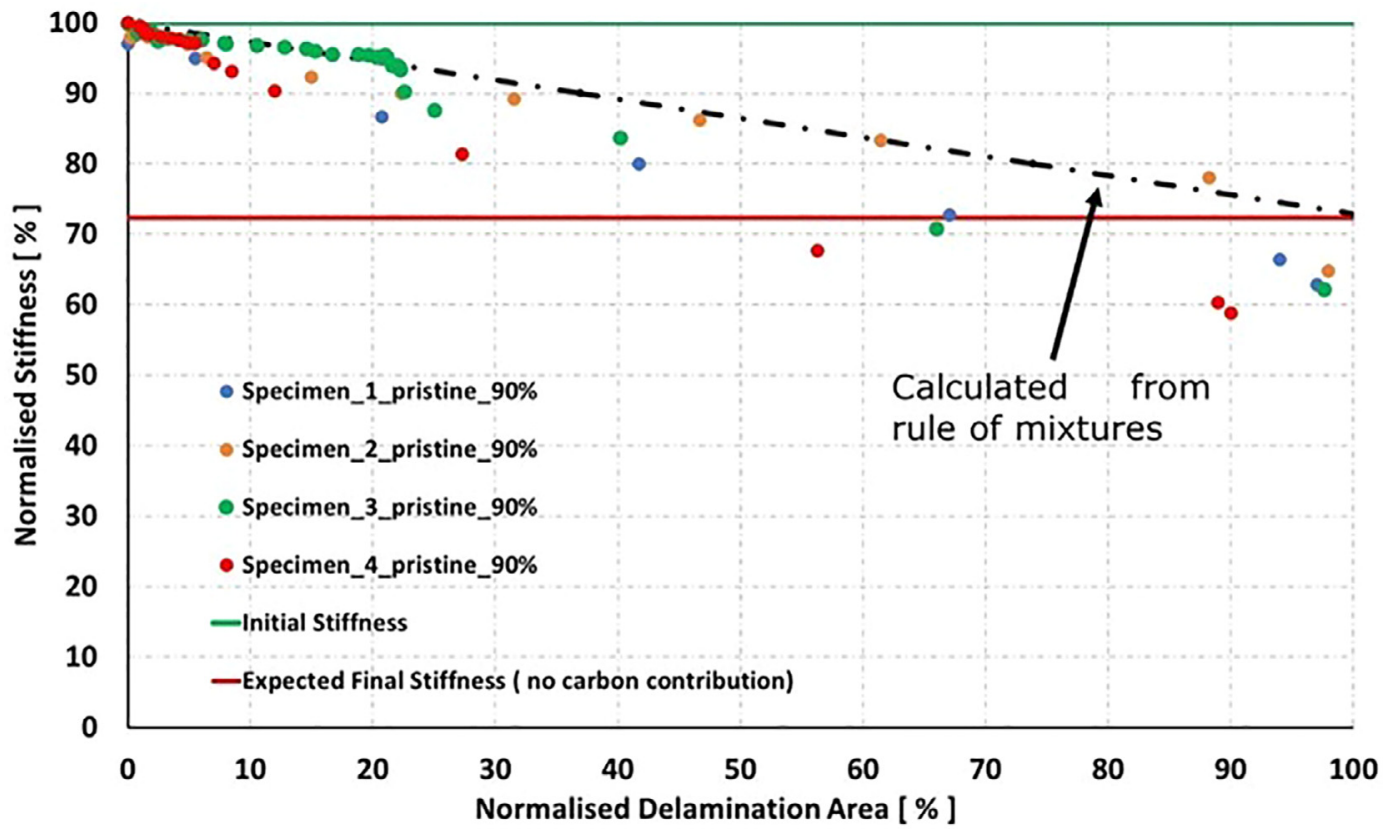

Fig. 5. Stiffness and delamination area relationship for UD pristine hybrid at $90 \%$ of $\sigma_{\mathrm{k}}$. 
Table 4

Stiffness loss rates with transition $\left(\mathrm{N}_{\mathrm{kp}}\right)$ and final number of cycles $\left(\mathrm{N}_{\mathrm{fp}}\right)$ summary for all 4 pristine hybrid composite specimens tested at $90 \%$ of $\sigma_{\mathrm{k}}$ (Numbers in brackets indicates the coefficient of variation in relative \%).

\begin{tabular}{llllll}
\hline $\begin{array}{l}\text { Specimen } \\
\text { number }\end{array}$ & $\begin{array}{l}\text { Stage 1 } \\
\% / 1000 \\
\text { cycles }\end{array}$ & $\begin{array}{l}\text { Stage 2 } \\
\% / 1000 \\
\text { cycles }\end{array}$ & $\begin{array}{l}\text { Stage 3 } \\
\% / 1000 \\
\text { cycles }\end{array}$ & $\begin{array}{l}\mathrm{N}_{\mathrm{kp}} \\
\text { Cycles }\end{array}$ & $\begin{array}{l}\mathrm{N}_{\mathrm{fp}} \\
\text { Cycles }\end{array}$ \\
\hline 1 & -0.00 & -0.45 & -3.66 & $35 \times 10^{3}$ & $45.74 \times 10^{3}$ \\
2 & -0.06 & -0.34 & -4.39 & $38.19 \times 10^{3}$ & $44.40 \times 10^{3}$ \\
3 & -0.05 & -0.26 & -3.34 & $99.63 \times 10^{3}$ & $11 \times 10^{4}$ \\
4 & -0.04 & -0.42 & -5.47 & $33.10 \times 10^{3}$ & $36.50 \times 10^{3}$ \\
average & -0.04 & -0.36 & -4.21 & $51.48 \times 10^{3}$ & $59.16 \times 10^{3}$ \\
& $(26 \%)$ & $(23 \%)$ & $(22 \%)$ & $(62 \%)$ & $(57 \%)$ \\
\hline
\end{tabular}

Table 5

Delamination growth rates summary for all 4 pristine hybrid composite specimens tested at $90 \%$ of $\sigma_{\mathrm{k}}$ (Numbers in brackets indicates the coefficient of variation in relative $\%)$.

\begin{tabular}{llll}
\hline Specimen number & $\begin{array}{l}\text { Stage } 1 \\
\% / 1000 \text { cycles }\end{array}$ & $\begin{array}{l}\text { Stage } 2 \\
\% / 1000 \text { cycles }\end{array}$ & $\begin{array}{l}\text { Stage } 3 \\
\% / 1000 \text { cycles }\end{array}$ \\
\hline 1 & 0.00 & 0.85 & 13.00 \\
2 & 0.01 & 0.64 & 13.20 \\
3 & 0.03 & 0.44 & 8.40 \\
4 & 0.02 & 0.76 & 17.54 \\
average & $0.02(22 \%)$ & $0.67(26 \%)$ & $13.04(28 \%)$ \\
\hline
\end{tabular}

Table 6

Stiffness loss rates with transition $\left(\mathrm{N}_{\mathrm{ko}}\right)$ and final number of cycles $\left(\mathrm{N}_{\mathrm{fo}}\right)$ summary for overloaded hybrid composites (numbers in brackets indicates the coefficient of variation in relative \%).

\begin{tabular}{lllllll}
\hline $\begin{array}{l}\text { Load } \\
\text { level } \\
{[\%]}\end{array}$ & $\begin{array}{l}\text { Specimen } \\
\text { number }\end{array}$ & $\begin{array}{l}\text { Stage 3 } \\
\% / 1000 \\
\text { cycles }\end{array}$ & $\begin{array}{l}\text { Stage 4 } \\
\% / 1000 \\
\text { cycles }\end{array}$ & $\begin{array}{l}\text { Stage 5 } \\
\% / 1000 \\
\text { cycles }\end{array}$ & $\begin{array}{l}\mathrm{N}_{\mathrm{ko}} \\
\text { Cycles }\end{array}$ & $\begin{array}{l}\mathrm{N}_{\mathrm{fo}} \\
\text { Cycles }\end{array}$ \\
\hline 70 & 13 & -0.30 & -0.20 & - & $8.24 \times 10^{3}$ & $72 \times 10^{3 \mathrm{a}}$ \\
& 15 & -0.78 & -0.36 & -0.14 & $12.48 \times 10^{3}$ & $54 \times 10^{3}$ \\
& 17 & -0.92 & -0.20 & -0.06 & $13.47 \times 10^{3}$ & $82 \times 10^{3}$ \\
& average & -0.66 & -0.25 & -0.10 & $11.39 \times 10^{3}$ & $68 \times 10^{3}$ \\
& & $(48 \%)$ & $(37 \%)$ & $(58 \%)$ & $(24 \%)$ & $(29 \%)$ \\
80 & 5 & -3.66 & -0.80 & -0.16 & $5.50 \times 10^{3}$ & $20 \times 10^{3}$ \\
& 6 & -6.23 & -1.87 & -0.34 & $1.94 \times 10^{3}$ & $10 \times 10^{3}$ \\
& 7 & -2.70 & -1.44 & -0.36 & $4.20 \times 10^{3}$ & $12 \times 10^{3}$ \\
& 8 & -4.00 & -1.53 & -0.38 & $4.80 \times 10^{3}$ & $30 \times 10^{3}$ \\
& average & -4.15 & -1.41 & -0.31 & $4.11 \times 10^{3}$ & $18 \times 10^{3}$ \\
& & $(36 \%)$ & $(31 \%)$ & $(32 \%)$ & $(37 \%)$ & $(50 \%)$ \\
90 & 1 & -15.30 & -6.01 & -1.30 & $1.02 \times 10^{3}$ & $4.4 \times 10^{3}$ \\
& 2 & -8.60 & -7.13 & -1.00 & $0.98 \times 10^{3}$ & $3.0 \times 10^{3}$ \\
& 3 & -10.10 & -4.02 & -0.67 & $1.05 \times 10^{3}$ & $4.6 \times 10^{3}$ \\
& 4 & -11.20 & -4.48 & -0.86 & $1.70 \times 10^{3}$ & $10.8 \times 10^{3}$ \\
& average & -11.45 & -5.41 & -0.95 & $1.18 \times 10^{3}$ & $5.7 \times 10^{3}$ \\
& & $(27 \%)$ & $(26 \%)$ & $(26 \%)$ & $(29 \%)$ & $(61 \%)$ \\
\hline
\end{tabular}

afatigue testing was terminated before the specimen was fully delaminated.

the Coefficient of Variation (CV) from Tables 4-8, the CV on final number of cycles of $29-61 \%$ is actually quite low compared to other published work, e.g. 57-166\% reported in Wu et al. [30]. While the CV on delamination growth rates of $22-58 \%$ is also low compared to $100-198 \%$ reported in Wisnom et al. [45].

\subsubsection{Failure modes}

During cyclic loading at $90 \%$ of $\sigma_{\mathrm{k}}$, the delamination growth is visible due to the translucent nature of the glass plies. This is an advantage as it is possible to monitor the delamination growth visually. Typical delamination growth as a function of load cycles is shown in Fig. 4, where in general, there is negligible delamination growth at stage 1 , a slow growth of delamination at stage 2 , followed by faster
Table 7

Delamination growth rates summary for overloaded hybrid composites (Numbers in brackets indicate the coefficient of variation in relative \%).

\begin{tabular}{lllll}
\hline $\begin{array}{l}\text { Load level } \\
{[\%]}\end{array}$ & $\begin{array}{l}\text { Specimen } \\
\text { number }\end{array}$ & $\begin{array}{l}\text { Stage } 3 \\
\% / 1000 \\
\text { cycles }\end{array}$ & $\begin{array}{l}\text { Stage } 4 \\
\% / 1000 \\
\text { cycles }\end{array}$ & $\begin{array}{l}\text { Stage } 5 \\
\% / 1000 \text { cycles }\end{array}$ \\
\hline 70 & 13 & 1.00 & 0.81 & - \\
& 15 & 3.26 & 0.90 & 0.07 \\
& 17 & 2.49 & 0.89 & 0.10 \\
& average & $2.25(51 \%)$ & $0.86(6 \%)$ & $0.08(25 \%)$ \\
80 & 5 & 11.68 & 4.44 & 0.10 \\
& 6 & 14.07 & 5.53 & 0.11 \\
& 7 & 12.10 & 7.30 & 0.13 \\
& 8 & 16.80 & 6.67 & 0.13 \\
90 & $13.66(17 \%)$ & $5.9(21 \%)$ & $0.11(12 \%)$ \\
& average & & 23.05 & 0.54 \\
& 1 & 46.47 & 19.67 & 0.59 \\
& 2 & 39.38 & 21.00 & 0.49 \\
& 3 & 34.80 & 11.15 & 0.30 \\
& 4 & 33.00 & $18.71(28 \%)$ & $0.48(26 \%)$
\end{tabular}

Table 8

Delamination growth rates and cyclic energy release rate summary for overloaded hybrid composites (numbers in brackets indicate the coefficient of variation in relative \%).

\begin{tabular}{llll}
\hline $\begin{array}{l}\text { Load level } \\
{[\%]}\end{array}$ & Specimen number & $\begin{array}{l}\text { Delamination growth rate } \\
\text { mm/cycle }\end{array}$ & $\begin{array}{l}\Delta \mathrm{G} \\
\mathrm{N} / \mathrm{mm}\end{array}$ \\
\hline 70 & 13 & 0.0012 & 0.30 \\
& 15 & 0.0010 & 0.41 \\
& 17 & 0.0009 & 0.41 \\
& average & $0.0010(14 \%)$ & $0.37(17 \%)$ \\
80 & 5 & 0.015 & 0.46 \\
& 6 & 0.026 & 0.55 \\
& 7 & 0.014 & 0.49 \\
& 8 & 0.020 & 0.54 \\
90 & average & $0.019(29 \%)$ & $0.51(8 \%)$ \\
& 1 & 0.055 & 0.64 \\
& 2 & 0.043 & 0.67 \\
& 3 & 0.041 & 0.52 \\
& 4 & 0.039 & 0.53 \\
& average & $0.045(16 \%)$ & $0.59(13 \%)$ \\
\hline
\end{tabular}

growth at stage 3 . Between stage 2 and stage 3 delamination growth, there is a transition point which has already been defined in section 6.2.1. The summary of delamination growth rates at $90 \%$ of $\sigma_{\mathrm{k}}$ at the three different stages is shown in Table 5. It is worth mentioning that the method to measure the delamination growth rates is also the same as the method to measure the stiffness loss rates mentioned in Section 6.2.1.

It is shown in Table 5 that there is considerable scatter in the delamination growth rate at all three stages, this behaviour could be attributed to statistical strength distribution of the carbon fibres [39] and the variability in the carbon layer thickness [46] in each hybrid specimen. Fig. 6 shows typical damage development in a UD pristine hybrid specimen fatigued at $90 \%$ of $\sigma_{k}$, where it is shown that the carbon fractures and delamination at $32.5 \times 10^{3}$ cycles do not develop across the full width of the specimen. It is also interesting to note that the carbon fractures also develop at different locations within the specimen's gauge length as seen for the damage development at $32.5 \times 10^{3}$ cycles in Fig. 6, because some individual fibres have failed early at those locations and developed into clusters of broken weak fibres via matrix damage or local debonding [47]. Each stage of damage development shown in Fig. 6 is linked to the specific stiffness loss stage shown in Fig. 4.

Looking at the damage behaviour at $2 \times 10^{4}$ cycles in Fig. 6, there is an initial very small patch of delamination (as shown by the red circle) 


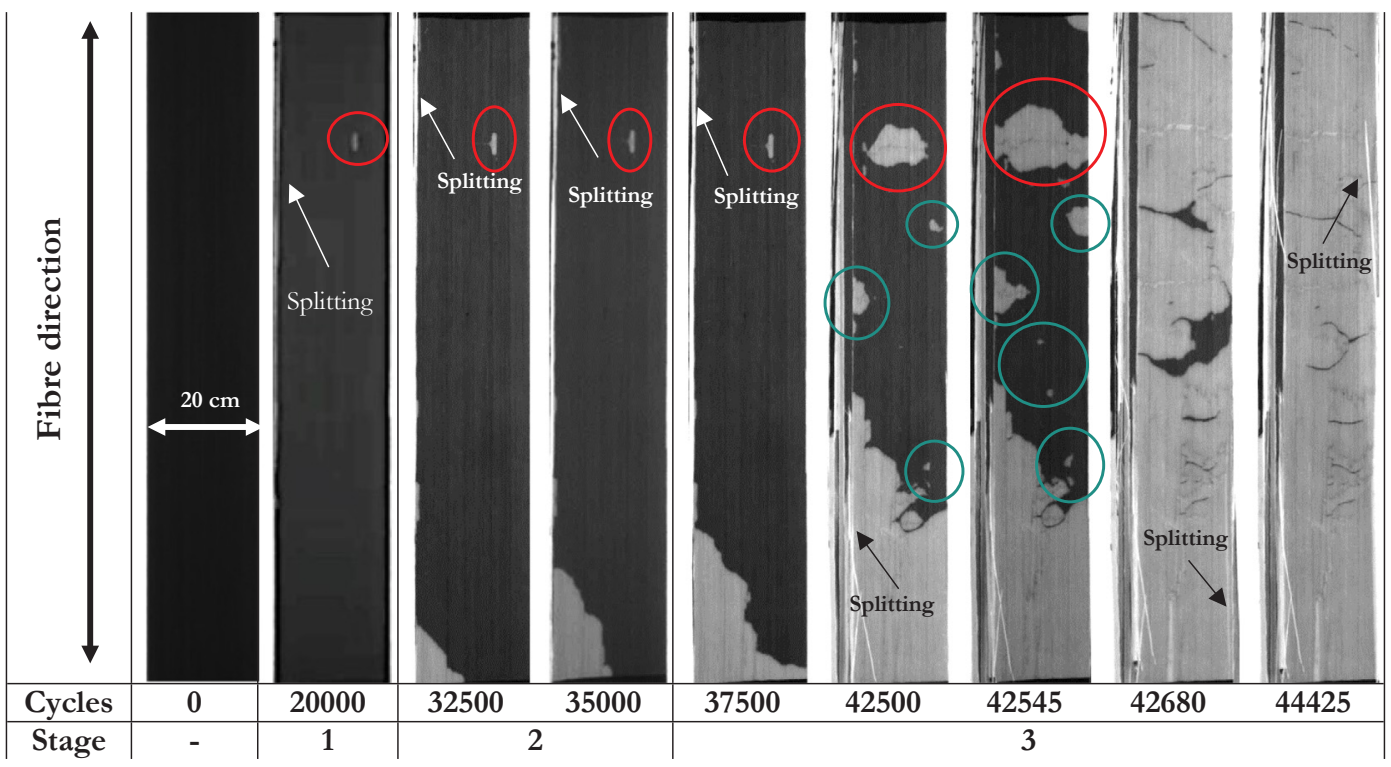

Fig. 6. Typical fatigue damage development for pristine UD thin-ply hybrid composite at $90 \% \sigma_{\mathrm{k}}$.

and minor splitting at the edge of the specimen (shown by the arrow). Although there is a small delaminated area at $2 \times 10^{4}$ cycles, it was not sufficient to cause a stiffness reduction, instead the splitting was responsible for the minor stiffness loss. At $32.5 \times 10^{3}$ cycles, the small delaminated area increases in size and there is a partial delamination at the bottom left corner (which is near the end tabs). The delamination at the left corner of this specimen grew with a slow rate when cycled from $25 \times 10^{3}$ to $35 \times 10^{3}$ cycles and this refers to stage 2 . From $32.5 \times 10^{3}$ to $35 \times 10^{3}$ cycles, the delamination originating at the left corner accelerated faster compared to the small patch. After reaching $37.5 \times 10^{3}$ cycles, the partial delamination from the left corner becomes established across the full width of the specimen, indicating that the carbon fracture has also extended. Splitting also took place during cyclic loading from $32.5 \times 10^{3}$ to $42.5 \times 10^{3}$ cycles, where the width of the split grew from approximately $0.4 \mathrm{~mm}$ to $3.9 \mathrm{~mm}$. From $37.5 \times 10^{3}$ to $42.5 \times 10^{3}$ cycles, the small patch area (as shown by the red circle) grew further, indicating that the corresponding carbon layer fracture has extended, while the delaminated area from the bottom part of the specimen has covered $25 \%$ of the area of the specimen. Small patches of delamination (shown by the green circles) also appeared at $42.5 \times 10^{3}$ cycles which originated from fragmented carbon layers. With increasing number of cycles from $42.545 \times 10^{3}$ to $44.425 \times 10^{3}$ cycles, the delaminated area which originated from the small patches grew in size along the specimen and eventually covered most of the specimen's surface at the final stage $\left(44.425 \times 10^{3}\right.$ cycles $)$. It was also observed that the width of splitting extended from approximately $4 \mathrm{~mm}$ to $6.6 \mathrm{~mm}$ during fatigue loading between $42.5 \times 10^{3}$ to $44.425 \times 10^{3}$ cycles. Based on the observed damage from the four hybrid specimens under fatigue loading at $90 \%$ of $\sigma_{\mathrm{k}}$, the stiffness loss shown in Fig. 4 during fatigue loading is mainly caused by fragmentation of carbon layers followed by the growth of delamination. At the final stage of fatigue loading, there is still some residual bonding between the carbon and glass layers, visible as a narrow black lines running across the width of the specimen. It should be noted that this residual bonding is too small to be able to transfer significant load.

\subsection{Fatigue behaviour of the overloaded UD thin-ply hybrid composites}

\subsubsection{Fatigue response}

Fig. 7 shows typical stiffness loss and delamination growth for an overloaded specimen pre-fractured until $2.3 \%$ strain and fatigued at $70 \%$ of $\sigma_{\mathrm{k}}$. This load level is chosen to be described first as it is representative of the fatigue behaviour of the other two load levels and allows a higher number of cycles and therefore can give better insight into damage development.

The initially normalised stiffnesses in Fig. 7 for all the overloaded hybrid composites do not start from $100 \%$ as there was already damage introduced in the form of fragmentation and dispersed delamination during the static overload, as shown in Fig. 8 for the damage state at 0 cycles. It should be noted that the fatigue damage development shown in Fig. 8 is related to each specific stiffness loss stage shown in Fig. 7.

There was a challenge to introduce a consistent extent of damage into the hybrid composites through a controlled static tension loading, and the initial amount of damage in terms of delaminated area between specimens differed. One of the reasons contributing to this behaviour is the local variation in the carbon layer thicknesses, where the hybrid specimens with thinner central carbon layers tend to have a finer distribution of fragmentation and smaller delamination area while for thicker central layers, a coarser distribution of damage was observed. During static tension loading, the initial amount of damage introduced in the hybrid composites was visually monitored. When the delaminated area had covered around $10 \%-20 \%$ of the total surface, the loading was stopped, and this was found to be related to approximately $95 \%-90 \%$ of the initial hybrid composite stiffness. Because there was already an initial damage in the hybrid specimens across the full width, when they were fatigued, the normalised stiffness reduction enters directly into the stage of rapid stiffness loss equivalent to stage 3 of the UD pristine hybrid shown in Fig. 4. After the delaminated area had covered $55-89 \%$ of the total surface, a transition point, $\mathrm{N}_{\mathrm{ko}}$, is reached where the stiffness loss rate decelerates in stage 4 because a reduced area is available for delamination. The transition point, $\mathrm{N}_{\mathrm{ko}}$, for the overloaded hybrid is determined from the intersection point of the linear lines fitted to the accelerated stiffness loss at stage 3 and decelerated stiffness loss at stage 4 respectively as shown in Fig. 7. After this particular specimen delaminated, the fatigue test was kept going until $54 \times 10^{3}$ cycles to see if the glass layers would fail but they did not, so the test was stopped. This shows that the glass layers could still carry the load even after the carbon layers had already fractured and delaminated. This is shown as stage 5 in Fig. 7, where a lower slope is reached for the stiffness loss and delamination growth rate because only a limited area is available for further delamination to occur and the load is mainly carried by the glass layers. The fatigue testing for the remaining overloaded UD hybrid composites at the three load levels was terminated at the final loading cycles, $\mathrm{N}_{\mathrm{fo}}$, when the specimens 


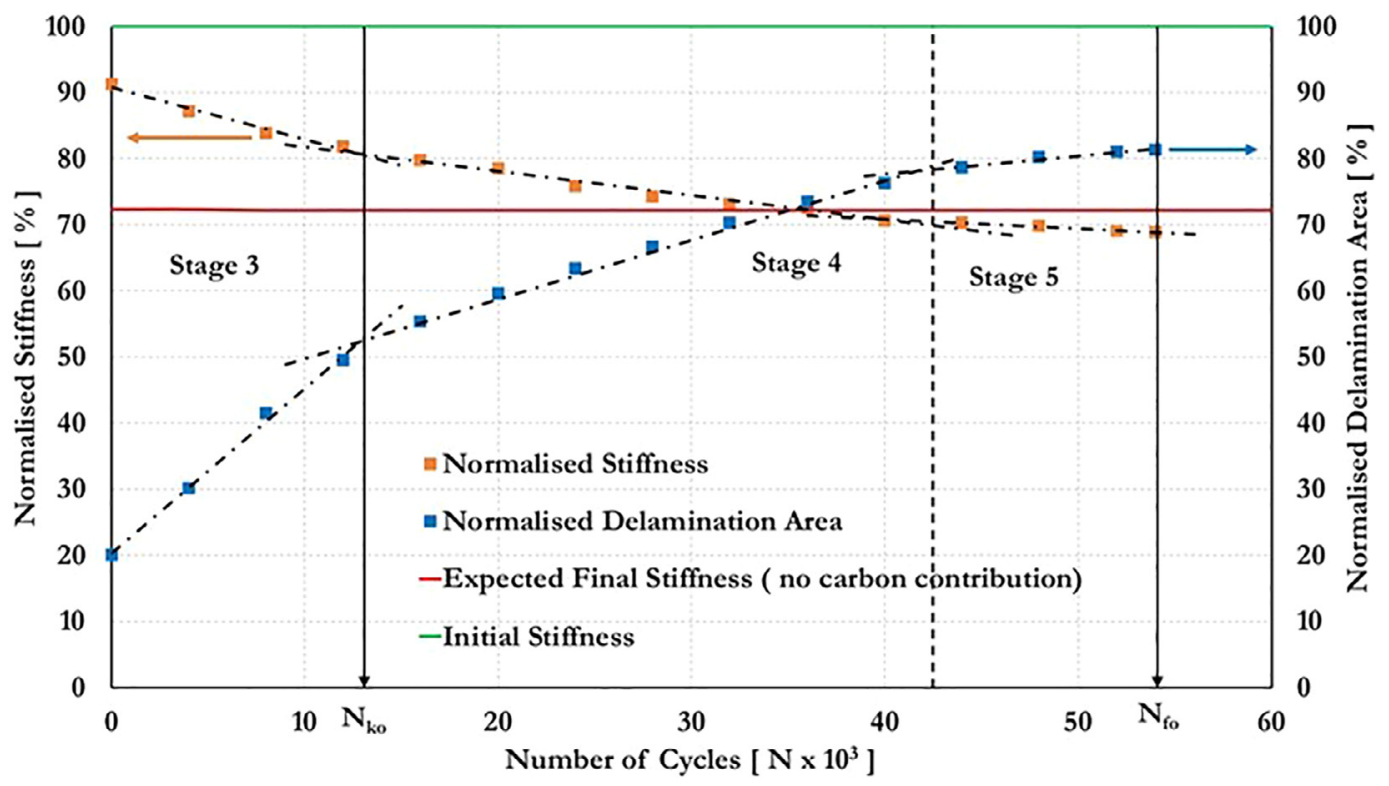

Fig. 7. Typical stiffness loss and delamination area development for UD overloaded hybrid at $70 \%$ of $\sigma_{\mathrm{k}}$.

were fully delaminated.

The comparison of typical stiffness losses for the three different fatigue load levels for the UD hybrid specimens is shown in Fig. 9 which indicates the dependency of stiffness loss on load level with significantly faster loss of stiffness at $90 \%$ of $\sigma_{\mathrm{k}}$ compared to the other two load levels. It is also shown in Fig. 9 that even when the hybrid composites lose the carbon layers contribution when fatigued at $80 \%$ and $90 \%$ of $\sigma_{\mathrm{k}}$, it did not fail immediately because the glass layers were still carrying the load.

The three stages of stiffness loss for $80 \%$ and $90 \%$ of $\sigma_{\mathrm{k}}$ are compacted in Fig. 9 due to the scale chosen but are similar to those at $70 \%$ of $\sigma_{\mathrm{k}}$. For the UD overloaded hybrid specimens fatigued in stage 3 , the average stiffness loss rates were $-0.66 \% / 1000$ cycles, $-4.15 \% / 1000$ cycles, $-11.45 \% / 1000$ cycles for $70 \%, 80 \%$ and $90 \%$ of $\sigma_{\mathrm{k}}$ respectively. The stiffness loss rate in stage 3 for the UD overloaded hybrid specimens fatigued at $90 \%$ of $\sigma_{\mathrm{k}}$ is approximately $40 \%$ higher than the loss rate for the UD pristine hybrid specimens fatigued at the same load level because there are already more carbon layer fractures in a well distributed pattern which act as sites for delamination propagation. The delamination growth rate is therefore also higher for the UD overloaded hybrids compared to the pristine ones. For all the UD overloaded hybrid specimens tested at the three load levels, the stiffness loss is mainly due to propagation of delamination. As shown in Fig. 7 the final stiffness of the hybrids went below the expected final stiffness without the carbon contribution due to splitting from the edge of the specimens. The summary of stiffness loss rates at stages 3,4 and 5 respectively for overloaded UD thin-ply hybrid composites with transition points $\left(\mathrm{N}_{\mathrm{ko}}\right)$ and final loading cycles $\left(\mathrm{N}_{\mathrm{fo}}\right)$ described in terms of the number of cycles is shown in Table 6 .

For specimen 13 shown in Table 6, the fatigue testing was terminated before full delamination was attained due to a sudden fault in the testing machine. The noticeable scatter in the stiffness loss rate shown

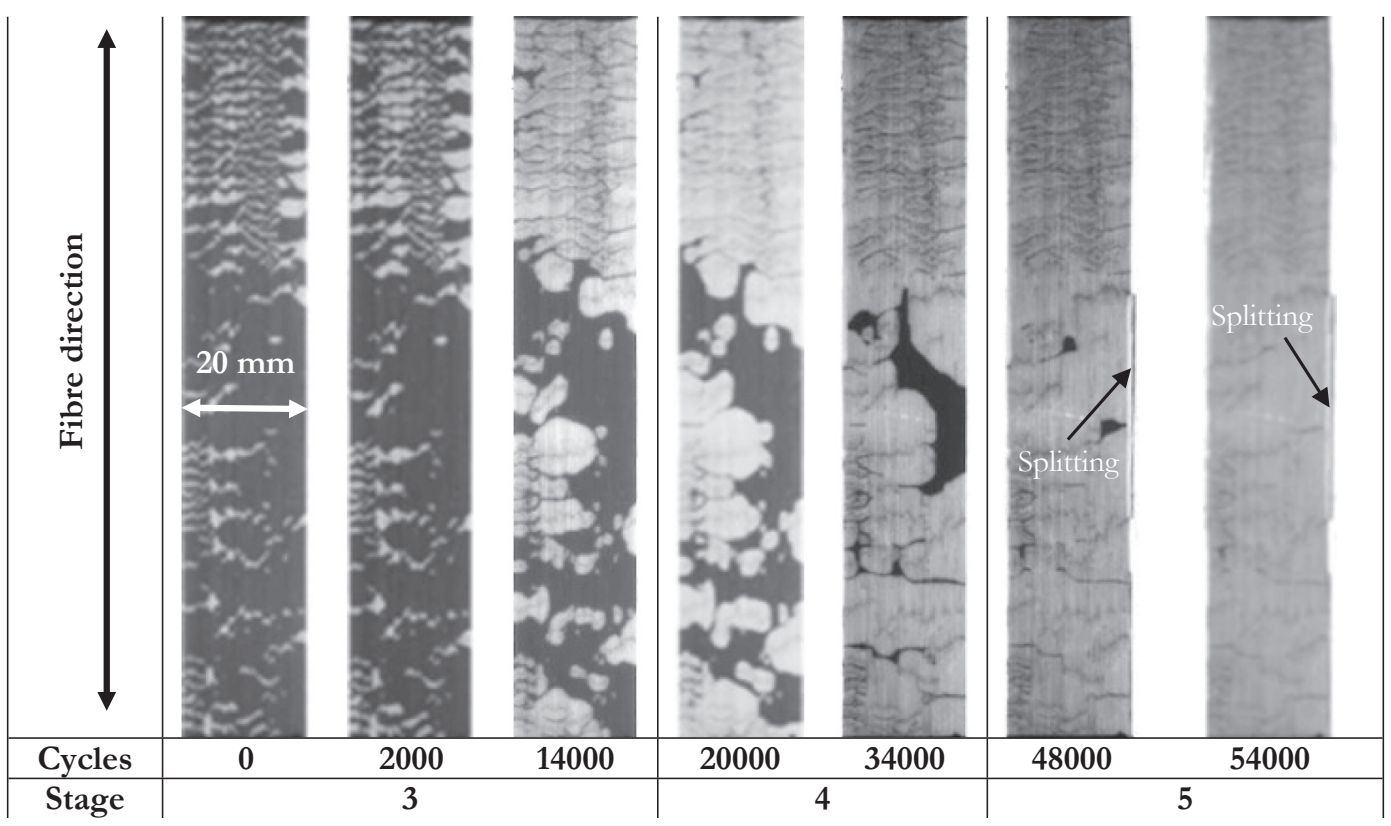

Fig. 8. Typical fatigue damage development for overloaded UD thin-ply hybrid composites at $70 \%$ of $\sigma_{\mathrm{k}}$. 


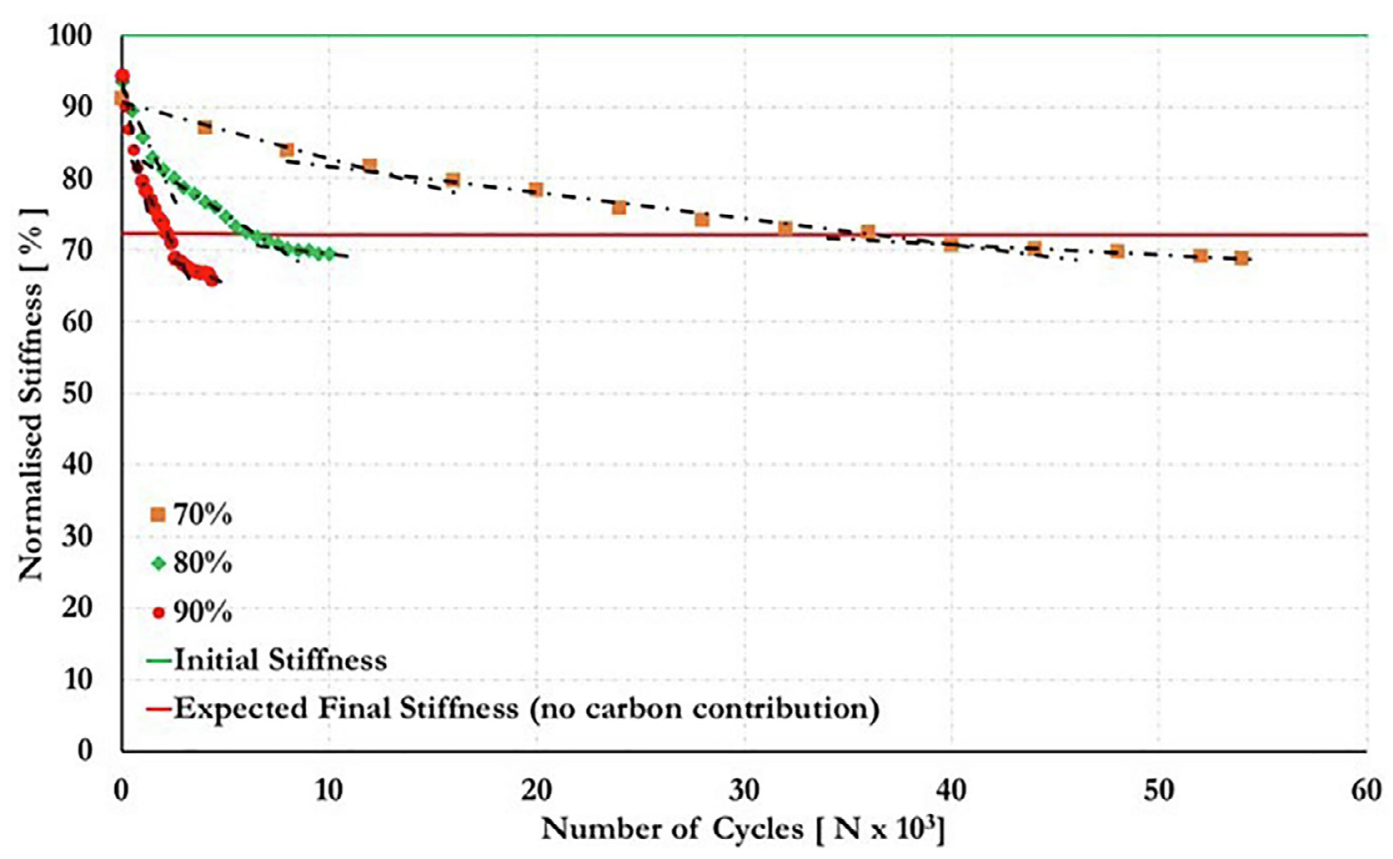

Fig. 9. Stiffness loss comparison for UD overloaded hybrids at $90 \%, 80 \%$ and $70 \%$ of $\sigma_{\mathrm{k}}$.

in Table 6 is due to variability of the initial damage between specimens and different extents of splitting. The faster stiffness loss rate of the overloaded UD hybrid composites at higher load levels is mainly due to the higher cyclic energy release rate.

\subsubsection{Failure modes}

The damage modes of the overloaded UD thin-ply hybrid composites at $70 \%, 80 \%$ and $90 \%$ of $\sigma_{\mathrm{k}}$ consist mainly of delamination growing from the multiple fragmentation sites. The delamination growth as a $\%$ of the total area is taken as the damage parameter because when a hybrid composite is fully delaminated, it has lost the load carrying capability of the stiffer carbon layers. Comparison of delamination growth as a function of load cycles for the three loading levels is shown in Fig. 10, where an accelerated growth rate for a number of cycles is followed by reduced growth rate. As already shown in Fig. 7 for specimens fatigued at $70 \%$ of $\sigma_{\mathrm{k}}$, there are three stages of delamination growth rate for overloaded UD hybrid composites which also apply for the damage growth rate at $80 \%$ and $90 \%$ of $\sigma_{\mathrm{k}}$. The delamination growth rates at the three stages were measured by applying a linear fit to the respective data as shown in Fig. 10 for the three-fatigue loading levels.

Typical damage development in an overloaded UD thin-ply hybrid composites is shown in Fig. 8. This is representative of the fatigue damage accumulation of all specimens at $70 \%, 80 \%$ and $90 \%$ of $\sigma_{\mathrm{k}}$. As shown in Fig. 8, at 0 cycles, after static tension loading had been applied, initial damage in the form of fragmentation and delamination was present in the specimen. It was noticeable that the fractured areas had irregular and staggered shape and the corresponding delamination

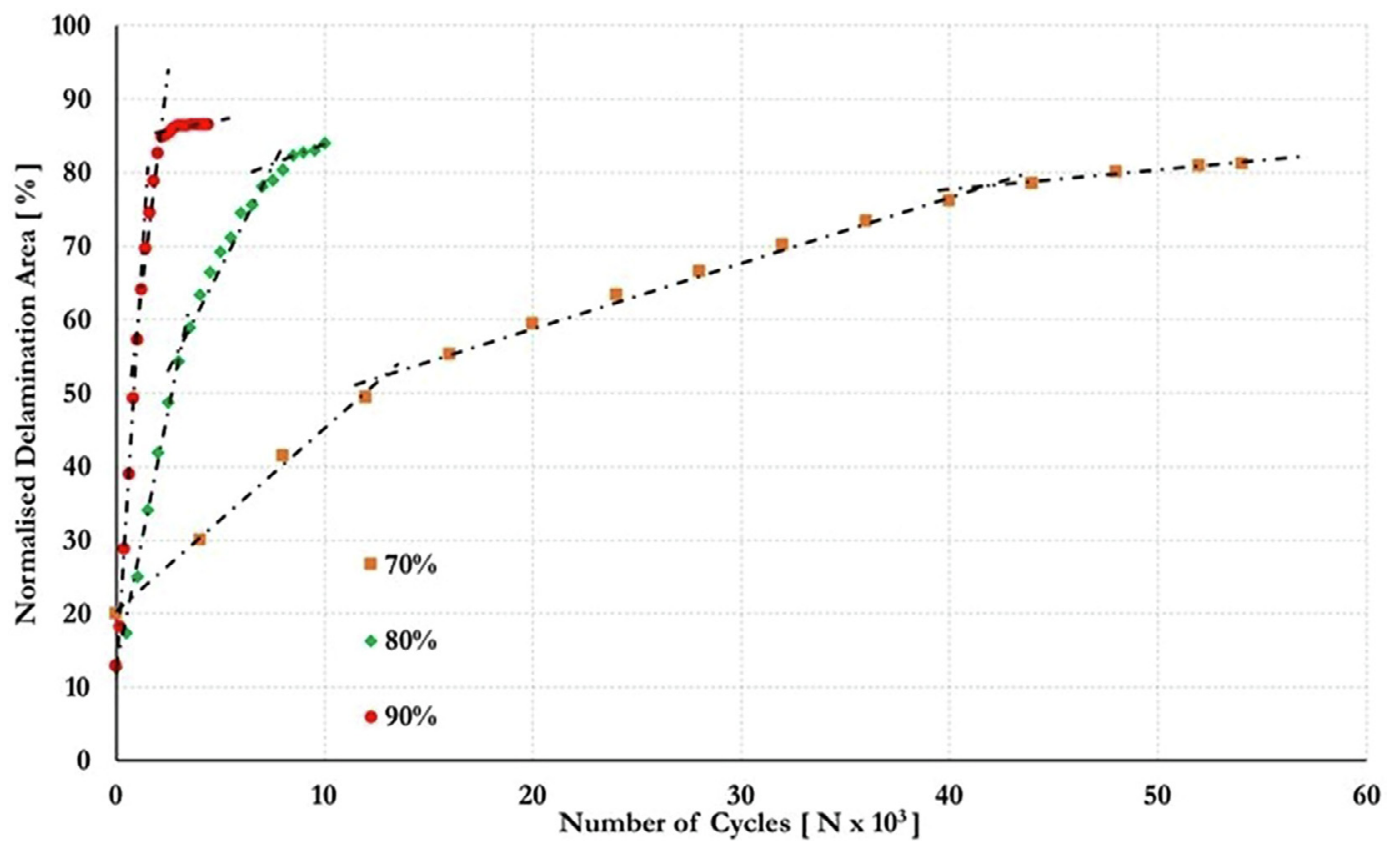

Fig. 10. Typical delamination development curve for overloaded UD thin-ply hybrid at $70 \%, 80 \%, 90 \%$ of $\sigma_{\mathrm{k}}$. 
areas covered around $20 \%$ of the specimen's surface. Most of them did not develop into a single linear crack front across the complete specimen width. The lighter delaminated areas around the carbon layer fractures also indicated various crack densities, with the fine areas corresponding to the thinner parts of the central carbon layers while the more coarsely cracked areas show the thicker parts, highlighting the thickness variability of the thin carbon prepreg. With increasing number of cycles at constant amplitude fatigue loading, the delaminated areas surrounding the fragmentations grew stably and joined with the neighbouring delamination areas as seen in Fig. 8 at stage 3. It is interesting to note that even though some of the carbon layer crack lengths are initially less than the full specimen width, the surrounding delamination areas were still able to grow because with advancing number of cycles, the carbon crack lengths were able to extend further. The normalised delamination growth rates shown in Fig. 10 for the three load levels display an initial accelerated growth rate followed by a reduced growth rate due to less area available for delamination to progress. It was also observed that splitting occurred for the majority of the UD overloaded hybrid specimens tested in fatigue causing a minor reduction in stiffness. Table 7 shows the summary of delamination growth rates for the overloaded UD thin-ply hybrid composites at the three different fatigue loading levels.

\subsubsection{Delamination growth rates as a function of cyclic energy release rates}

It is possible to correlate the delamination growth rate with the cyclic energy release rate at a constant load level to quantify the life of the overloaded UD hybrid composites under fatigue loading by adopting a Paris law type equation, assuming growth in a self-similar manner as shown in Eq. (9):

$\frac{d a}{d N}=C(\Delta G)^{m}$

where a is the delamination length, $N$ is the number of cycles, $\Delta \mathrm{G}$ is the cyclic energy release rate, and $\mathrm{C}$ and $\mathrm{m}$ are parameters that characterise the propagation rate. This assumes that the delamination length grows linearly with advancing number of cycles at constant-amplitude loading. The parameters $\mathrm{C}$ and $\mathrm{m}$ need to be determined to have a complete relation of Eq. (9) by plotting the delamination growth rates in $\mathrm{mm} / \mathrm{cycle}$ as a function of cyclic energy release rates. This plot on a logarithmic scale is shown in Fig. 11 for the three fatigue load levels. The delamination growth rate, $\mathrm{da} / \mathrm{dN}$, is determined from the linear portion of the plot of normalised delamination area versus number of cycles under each constant load amplitude. The linear portion is fitted with a line as shown in Fig. 10 and the initial linear portion (stage 3) is used as the delamination growth rate, da/dN, plot in Fig. 11. It should be noted that the delamination growth rates shown in Table 7 which are in \%/ 1000 cycles needs to be converted to $\mathrm{mm} /$ cycle. Table 8 shows the summary of delamination growth rate in $\mathrm{mm}$ /cycle with the cyclic

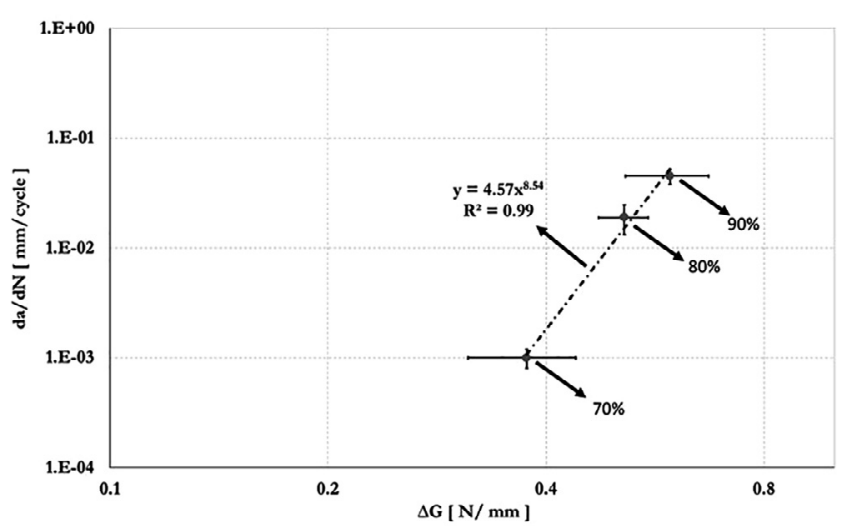

Fig. 11. Delamination growth per cycle as a function of cyclic energy release rates for overloaded UD thin-ply hybrid composites at $70 \%, 80 \%, 90 \%$ of $\sigma_{\mathrm{k}}$. energy release rate at the three-load levels which is used to reproduce the plot in Fig. 11.

As seen in Table 8, there are slight differences between the cyclic energy release rates at the same loading level. The reason behind this is because the load levels were taken as fixed percentages of the different values of knee-point stress, $\sigma_{\mathrm{k}}$, for each hybrid specimen.

As seen in Fig. 11 the $C$ and m parameters are 4.57 and 8.54 respectively and although there are only three points, the fit to a straight line is good, which implies that the delamination growth rates as a function of cyclic energy release rates comply with the Paris law in Equation (9). This could be used as a basis for life estimation during fatigue loading of UD thin-ply hybrid composites. There is a wide range of Paris law parameters for fibre reinforced composites, but none published for this material. The exponent, $\mathrm{m}$, of 8.54 lies within the range from 3.1 to 9.6 reported for other carbon fibre/epoxy materials $[35,45,48,49]$.

\section{Conclusions}

This paper has presented the mechanical properties of unidirectional thin-ply hybrid composites subjected to static and cyclic tensile loads. The effect of different loading conditions was examined. The following was concluded:

1. When pristine hybrid specimens were fatigued at $80 \%$ of $\sigma_{\mathrm{k}}$ no stiffness reduction up until $10^{5}$ cycles was observed because the specimens were loaded well below the first carbon layer fracture strain.

2. It was observed that there are three stages of damage growth when UD pristine hybrid specimens are fatigued at $90 \%$ of $\sigma_{\mathrm{k}}$. The first stage has negligible stiffness loss, the second stage involves slow growth of delamination from fragmentations, and the third stage when the delamination becomes established across the full width, with higher delamination rate.

3. For the overloaded hybrid composites, there are three stages of damage growth. The initial stage, which is equivalent to the third stage for the UD pristine hybrid specimens, involves rapid stiffness loss and accelerated delamination growth from the existing initial fractures, the next stage with slower stiffness loss due to delamination approaching saturation, and the last stage with negligible stiffness loss rate when the specimen is fully delaminated, but the glass layers are still able to carry the load. When the overloaded hybrid laminates were fatigued at $70 \%$ and $80 \%$ of $\sigma_{\mathrm{k}}$, they showed more gradual stiffness reduction and slower damage growth compared to the fatigued overloaded hybrids at $90 \%$ load level.

4. The stiffness loss rate of the overloaded UD thin-ply hybrid composites fatigued at $90 \%$ of $\sigma_{\mathrm{k}}$ is higher compared to the pristine UD thin-ply hybrid composites because there are already more carbon layer fractures in a well distributed pattern which act as sites for delamination propagation.

5. Delamination growth as a function of strain energy release rate for overloaded UD thin-ply hybrid composites complies with the Paris law and this could be used as the basis for life estimation.

\section{Acknowledgement}

This work was funded under the UK Engineering and Physical Sciences Research Council Programme Grant EP/I02946X/1 on High Performance Ductile Composite Technology in collaboration with Imperial College, London. Putu Suwarta acknowledges The Directorate General of Higher Education of the Ministry of Education and Culture of the Republic of Indonesia (DIKTI) for funding through the DIKTI scholarship. Gergely Czél acknowledges the Hungarian National Research, Development and Innovation Office (NKFIH) for funding through grants ref. OTKA K 116070 and OTKA PD 121121, the Hungarian Academy of Sciences for funding through the János Bolyai 
scholarship and the Hungarian Ministry of Human Capacities (EMMI) for funding through the BME-Nanonotechnology FIKP grant (BME FIKPNAT). The authors acknowledge Hexcel Corporation and SK Chemical for supplying materials for this research. Supporting data can be requested from the corresponding author.

\section{Appendix A. Supplementary data}

Supplementary data to this article can be found online at https:// doi.org/10.1016/j.compstruct.2019.110996.

\section{References}

[1] Edwards KL. An overview of the technology of fibre-reinforced plastics for design purposes. Mater Des 2002;19(1-2):1-10.

[2] Mishnaevsky L, Branner K, Petersen HN, Beauson J, McGugan M, Sørensen BF. Materials for wind turbine blades: an overview. Materials (Basel) 2017;10(11):1-24.

[3] Swanek DSS, Carey J. Braided composite materials for the production of lightweight, high rigidity golf shafts. Sport Eng 2010;10(4):195-208.

[4] Mangalgiri PD. Composite materials for aerospace applications. Bull Mater Sci 1999;22(3):657-64.

[5] Savage G. Composite materials technology in formula 1 motor racing. In: SPE Automot. Compos. Div. - 8th Annu. Automot. Compos. Conf. Exhib. ACCE 2008 Road to Light. Perform., vol. 1, no. July 2008, pp. 109-139, 2008.

[6] Gan KW, Wisnom MR, Hallett SR. Effect of high through-thickness compressive stress on fibre direction tensile strength of carbon/epoxy composite laminates. Compos Sci Technol 2014;90:1-8.

[7] Allaer K, De Baere I, Lava P, Van Paepegem W, Degrieck J. On the in-plane mechanical properties of stainless steel fibre reinforced ductile composites. Compos Sci Technol 2014;100:34-43.

[8] Callens MG, Gorbatikh L, Verpoest I. Ductile steel fibre composites with brittle and ductile matrices. Compos Part A Appl Sci Manuf 2014;61:235-44.

[9] Callens MG, Gorbatikh L, Bertels E, Goderis B, Smet M, Verpoest I. Tensile behaviour of stainless steel fibre/epoxy composites with modified adhesion. Compos Part A Appl Sci Manuf 2015;69:208-18.

[10] Callens MG, De Cuyper P, Gorbatikh L, Verpoest I. Effect of fibre architecture on the tensile and impact behaviour of ductile stainless steel fibre polypropylene composites. Compos Struct 2015;119:528-33.

[11] Swolfs Y, De Cuyper P, Callens MG, Verpoest I, Gorbatikh L. Hybridisation of two ductile materials - steel fibre and self-reinforced polypropylene composites. Compos Part A Appl Sci Manuf 2017;100:48-54.

[12] Boncel S, Sundaram RM, Windle AH, Koziol KKK. Enhancement of the mechanical properties of directly spun CNT fibers by chemical treatment. ACS Nano 2011;5(12):9339-44.

[13] Marom G, Fischer S, Tuler FR, Wagner HD. Hybrid effects in composites: conditions for positive or negative effects versus rule-of-mixtures behaviour. J Mater Sci 1978;13(7):1419-26.

[14] Svensson N, Shishoo R, Gilchrist M. Manufacturing of thermoplastic composites from commingled yarns-a review. J Thermoplast Compos Mater 1998;11(1):22-56.

[15] Wisnom M, Diao H, Bismarck A, Robinson P. Pseudo-ductile behaviour of unidirectional fibre reinforced polyamide- 12 composite by intra-tow hybridization. In: Proceedings of ECCM 15 conference, 2012.

[16] Hayashi T, Koyama K, Yamazaki A, Kihira M. Development of new material properties by hybrid composition. 1st report. Fukugo Zairyo (Compos Mater) 1972;1(1):18-20.

[17] Hayashi T, Koyama K, Yamazaki A, Kihira M. Development of new material properties by hybrid composition. 2nd report. Compos Mater 1972;21.

[18] Bunsell AR, Harris B. Hybrid carbon and glass fibre composites. Composites 1974;5(4):157-64.

[19] Manders PW, Bader MG. The strength of hybrid glass/carbon fibre composites Part 1 failure strain enhancement and failure mode. J Mater Sci 1981;16(8):2233-45.

[20] Sihn S, Kim RY, Kawabe K, Tsai SW. Experimental studies of thin-ply laminated composites. Compos Sci Technol 2007;67:996-1008.

[21] Yokozeki T, Aoki Y, Ogasawara T. Experimental characterization of strength and damage resistance properties of thin-ply carbon fiber/toughened epoxy laminates. Compos Struct 2008;82(3):382-9.

[22] Saito H, Morita M, Kawabe K, Kanesaki M, Takeuchi H, Tanaka M, et al. Effect of ply-thickness on impact damage morphology in CFRP laminates. J Reinf Plast Compos 2011;30(13):1097-106.

[23] Yokozeki T, Kuroda A, Yoshimura A, Ogasawara T, Aoki T. Damage characterization in thin-ply composite laminates under out-of-plane transverse loadings. Compos Struct 2010;93(1):49-57.

[24] Czél G, Wisnom MR. Demonstration of pseudo-ductility in high performance glass/ epoxy composites by hybridisation with thin-ply carbon prepreg. Compos Part A Appl Sci Manuf 2013;52:23-30.

[25] Czél G, Jalalvand M, Wisnom MR. Design and characterisation of advanced pseudoductile unidirectional thin-ply carbon/epoxy-glass/epoxy hybrid composites. Compos Struct 2016;143:362-70.

[26] Fotouhi M, Suwarta P, Jalalvand M, Czel G, Wisnom MR. Detection of fibre fracture and ply fragmentation in thin-ply UD carbon/glass hybrid laminates using acoustic emission. Compos Part A Appl Sci Manuf 2016;86:66-76.

[27] Jalalvand M, Czél G, Wisnom MR. Numerical modelling of the damage modes in UD thin carbon/glass hybrid laminates. Compos Sci Technol 2014;94:39-47.

[28] Jalalvand M, Czél G, Wisnom MR. Damage analysis of pseudo-ductile thin-ply UD hybrid composites - a new analytical method. Compos Part A Appl Sci Manuf 2015;69:83-93.

[29] Jalalvand M, Czél G, Wisnom MR. Parametric study of failure mechanisms and optimal configurations of pseudo-ductile thin-ply UD hybrid composites. Compos Part A Appl Sci Manuf 2015;74:123-31.

[30] Wu Z, Wang X, Iwashita K, Sasaki T, Hamaguchi Y. Tensile fatigue behaviour of FRP and hybrid FRP sheets. Compos Part B Eng 2010;41(5):396-402.

[31] Dickson RF, Fernando G, Adam T, Reiter H, Harris B. Fatigue behaviour of hybrid composites. J Mater Sci 1989;24:227-33.

[32] Peijs AAJM, de Kok JMM. Hybrid composites based on polyethylene and carbon fibres. Part 6: Tensile and fatigue behaviour. Composites 1993;24(1):19-32.

[33] Militký J, Kovačič V, Rubnerová J. Influence of thermal treatment on tensile failure of basalt fibers. Eng Fract Mech 2002;69(9):1025-33.

[34] Dai G, Mishnaevsky L. Fatigue of hybrid glass/carbon composites: 3D computational studies. Compos Sci Technol 2014;94:71-9.

[35] O'Brien TK. Characterization of delamination onset and growth in a composite laminate, Damage Compos. Mater. Basic Mech. Accumulation, Toler. Charact., p. 140-67, 1982.

[36] Suwarta P, Fotouhi M, Czel G, Wisnom MR. Fatigue behaviour of pseudo-ductile thin ply hybrid composites. In: 21st ICCM proceeding, p. 20-25, 2017.

[37] Czél G, Jalalvand M, Wisnom MR. Hybrid specimens eliminating stress concentrations in tensile and compressive testing of unidirectional composites. Compos Part A Appl Sci Manuf 2016;91:436-47.

[38] Czél G, Jalalvand M, Wisnom MR. Demonstration of pseudo-ductility in unidirectional hybrid composites made of discontinuous carbon/epoxy and continuous glass/epoxy plies. Compos Part A Appl Sci Manuf 2015;72:75-84.

[39] Wisnom MR, Czél G, Swolfs Y, Jalalvand M, Gorbatikh L, Verpoest I. Hybrid effects in thin ply carbon/glass unidirectional laminates: accurate experimental determination and prediction. Compos Part A Appl Sci Manuf 2016;88:131-9.

[40] Brien TKO, Reifsnider KL. Fatigue damage evaluation through stiffness measurements in boron-epoxy laminates, vol. 15, no. January, 1981.

[41] Jamison R, Schulte K, Reifsnider K, Stinchcomb W. Characterization and analysis of damage mechanisms in tension-tension fatigue of graphite/epoxy laminates. In: Eff. Defects Compos. Mater., pp. 21-21-35, 1984.

[42] Hahn HT, Kim RY. Fatigue behavior of composite laminate. J Compos Mater 1976;10(2):156-80.

[43] Wisnom MR, Jones M. Delamination of unidirectional glass fibre-epoxy with cut plies loaded in four point bending. J Reinf Plast Compos 1995;14:45-59.

[44] Czél G, Jalalvand M, Wisnom MR, Czigány T. Design and characterisation of high performance, pseudo-ductile all-carbon/epoxy unidirectional hybrid composites. Compos Part B Eng 2017;111:348-56.

[45] Wisnom MR, Jones MI, Cui W. Delamination in composites with terminating internal plies under tension fatigue loading. ASTM Spec Tech Publ 1995; 1230:486-508.

[46] Frossard G. Fracture of thin-ply composites effects of ply thickness, PhD thesis, vol. 8032, p. 188, 2017.

[47] Gamstedt EK, Talreja R. Fatigue damage mechanisms in unidirectional carbon-fibrereinforced plastics. J Mater Sci 1999;34(11):2535-46.

[48] Allegri G, Jones MI, Wisnom MR, Hallett SR. A new semi-empirical model for stress ratio effect on mode II fatigue delamination growth. Compos Part A Appl Sci Manuf 2011;42(7):733-40.

[49] Allegri G, Wisnom MR, Hallett SR. A new semi-empirical law for variable stressratio and mixed-mode fatigue delamination growth. Compos Part A Appl Sci Manuf 2013;48(1):192-200. 